or five inches from the bottom of the foot-piece. The foot-piece is shod underneath with a thickness of sole leather and pierced for the rivets to fasten two half-inch leather straps (F) by means of which traction is to be made. A coupling is inserted at D to provide for the lengthening of the splint as the child grows. It is more convenient to have two couplings in the upright so that the length of the splint may be changed by the insertion of a piece of pipe of varying length between them.

The semicircular arms $C$ and $E$ are forged out of flat malleable iron and fastened to the upright by a small screw as shown in the detail drawing $\mathbf{E}^{\prime}$. Rivets at each end attach a strap and bucklo to encircle and steady the leg.

The splint can be used either as a walking splint with a high shoe on the other foot, or as a traction splint pure and simple, by means of the use of crutches, not allowing the splint to touch the ground. Stout buckles with tongues should be attached to the lower ends of the adhesive plaster leg extension and the strap $F$ buckled into them. This form of traction is of course inferior to the steadily and easily graduated pull which one obtains by a windlass or a ratchet extension, but it seems enough for all practical purposes in the hands of reasonably careful people, and it is hoped that the cheapness and simplicity of the splint may commend it in instances where simplicity aud cheapness are essential.

\section{AN APPARATUS FOR THE CORRECTION OF TALIPES EQUINO VARUS.}

HY JOHN DANk,

House Surgeon of the Honse of the Good Samaritan.

Tne following is a description of a piece of apparatus which has been found useful in correcting talipes equino varus without tenotomy ; and in naintaining the foot in an over-corrected position after the operation. It is a modification of the snow-shoe method, which consists of a shingle, long enough to project beyond the toes for two or three inches, strapped to the sole of the foot, with a side arm rumning outwards at right augles to the foot. The heel is held firmly to the shiugle by means of bandages and adhesive-plaster straps running up the leg. 'The long projecting end of the shingle in front furvishes a lever by which to flex the foot. The flexion is obtained by means of tightening a strap; the upper end of which is put through a buckle fastened to the shin by adhesive plaster, and the lower end fastened to the front end of the shingle. Eversion of the foot is accomplished by a similar strap, extending from the end of the side arm to the middle of the leg.

The apparatus described here consists of a light frame, which replaces the plaster around the leg, and furnishes a basis for flexing the foot without obstruct. ing the circulation of the leg, as often happens with the method just described. It consists of three uprights connected by two semicircular posterior steel bauds. Each of these calf bands is furnished with a strap and buckle. 'The two side uprights have each two eyelets riveted to their sides; the posterior upright has but a single eyelet placed behind. The two buckles, which are to receive the straps that come from the toe and arm of the shingle, are sewed to the side of a piece of webbing of about eighteen inches in length. They should be side by side, and less than two inches from one end of the strip. 'To this end is also sewed another buckle, by which the strip can be buckled to itself. Furnished with its buckles, the long webbing is applied to the leg in the form of a figure-ofeight, passing through the several eyelets, as shown in the cut. This will bring the two buckles in front over the shin. 'Through these are passed the straps from the shingle and its arm. By tightening on these straps flexion and eversion may be obtained to any desired amount. The pressure will be so much distributed that it will not impede the venous circulation. Finally, the whole frame is not pulled down by the tension of the straps; for the more strain brought by them on the buckles, the tighter will it cause the webbing to which they are attached to grip the limb. The simplicity of this apparatus and its ready application are much in its favor.

\section{Reporti of Sacietieg.}

\section{BOSTON SOCIETY FOR MEDICAL IMPROVE- MEN'T.}

G. G. BEARg, M.D., BECRETARY.

Annual Meeting, Monday, January 12, 1891, Dr. W. L. Richandson in the chair.

ORAL COMMUNICATIONS.

PATHOLOGY OF HYSTERICAL JOINT DISEA'SE.

Dr. Morton Prince: I have here a case that I think of considerable interest, and also of practical importance, because it seems to me to throw light on the nature and pathology of so-called hysterical joint diseases. 'There is nothing very remarkable about the case in other respects.

This little girl I showed a year ago at a meeting of the Society for Medical Observation. She was then in just about the same condition that she is now. I had not seen her from that time until a short time ago when she presented the picture that you see. It has been quite puzzling to make out what was the real nature of the trouble. You will see that there is very decided atrophy of the muscles of the right leg and thigh. There is a contracture of the hamstring muscles, and in consequence the leg is held in a position of semiflexion. There has been pain in the knee-joint, but there is none now. There is a certain amount of deformity of the pelvis and the body due to an attempt to counterbalance the deformity of the leg. When I first saw her she walked on the ball of her foot, but she now plants the foot squarely on the ground. I have never been able to straighten the leg completely. She has been repeatedly examined by Dr. Burrell, Dr. Cushing and myself. No one has been able to detect any disease of the hip or knee joint, and yet she has not improved beyond what she did during the first few months, though she is much better than she was when I first saw her. Although the disability has been recognized as hysterical, it has been very difficult to understand the mechanism of the trouble. I think I have at last hit upon the true solution of the difficulty. Any attempt to straighten the leg has always resulted in severe spasm of the ham-string muscles. There is quite marked atrophy of the muscles of the leg and of the thigh muscles 80 that it measures one inch less at this height than its 